\title{
Gastrointestinal cancer incidence in type 2 diabetes mellitus; results from a large population-based cohort study in the UK
}

Citation for published version (APA):

de Jong, R. G. P. J., Peeters, P. J. H. L., Burden, A. M., de Bruin, M. L., Haak, H. R., Masclee, A. A. M., de Vries, F., \& Janssen-Heijnen, M. L. G. (2018). Gastrointestinal cancer incidence in type 2 diabetes mellitus; results from a large population-based cohort study in the UK. Cancer Epidemiology, 54, $104-111$. https://doi.org/10.1016/j.canep.2018.04.008

Document status and date:

Published: 01/06/2018

DOI:

10.1016/j.canep.2018.04.008

Document Version:

Publisher's PDF, also known as Version of record

Document license:

Taverne

Please check the document version of this publication:

- A submitted manuscript is the version of the article upon submission and before peer-review. There can be important differences between the submitted version and the official published version of record.

People interested in the research are advised to contact the author for the final version of the publication, or visit the DOI to the publisher's website.

- The final author version and the galley proof are versions of the publication after peer review.

- The final published version features the final layout of the paper including the volume, issue and page numbers.

Link to publication

\footnotetext{
General rights rights.

- You may freely distribute the URL identifying the publication in the public portal. please follow below link for the End User Agreement:

www.umlib.nl/taverne-license

Take down policy

If you believe that this document breaches copyright please contact us at:

repository@maastrichtuniversity.nl

providing details and we will investigate your claim.
}

Copyright and moral rights for the publications made accessible in the public portal are retained by the authors and/or other copyright owners and it is a condition of accessing publications that users recognise and abide by the legal requirements associated with these

- Users may download and print one copy of any publication from the public portal for the purpose of private study or research.

- You may not further distribute the material or use it for any profit-making activity or commercial gain

If the publication is distributed under the terms of Article $25 \mathrm{fa}$ of the Dutch Copyright Act, indicated by the "Taverne" license above, 


\title{
Gastrointestinal cancer incidence in type 2 diabetes mellitus; results from a large population-based cohort study in the UK
}

\author{
Roy G.P.J. de Jong, ${ }^{\mathrm{a}, \mathrm{b}, \mathrm{c}}$, Paul J.H.L. Peeters ${ }^{\mathrm{d}}$, Andrea M. Burden ${ }^{\mathrm{d}, \mathrm{e}}$, Marie L. de Bruin ${ }^{\mathrm{d}}$, \\ Harm R. Haak $^{\mathrm{f}, \mathrm{g}, \mathrm{h}}$, Ad A.M. Masclee ${ }^{\mathrm{c}, \mathrm{i}}$, Frank de Vries ${ }^{\mathrm{d}, \mathrm{e}, \mathrm{h}, \mathrm{j}, *}$, Maryska L.G. Janssen-Heijnen ${ }^{\mathrm{b}, \mathrm{k}}$ \\ a Department of Internal Medicine, VieCuri Medical Centre, Venlo, The Netherlands \\ ${ }^{\mathrm{b}}$ GROW School for Oncology and Developmental Biology, Maastricht University Medical Centre+, Maastricht, The Netherlands \\ ${ }^{\mathrm{c}}$ Department of Internal Medicine, Division of Gastroenterology and Hepatology, Maastricht University Medical Centre+, Maastricht, The Netherlands \\ d Utrecht Institute for Pharmaceutical Sciences, Division of Pharmacoepidemiology and Clinical Pharmacology, Utrecht University, Utrecht, The Netherlands \\ e Department of Clinical Pharmacy and Toxicology, Maastricht University Medical Centre +, Maastricht, The Netherlands \\ ${ }^{\mathrm{f}}$ Department of Internal Medicine, Máxima Medical Centre Eindhoven, Eindhoven, Netherlands \\ ${ }^{g}$ Department of Internal Medicine, Division of General Internal Medicine, Maastricht University Medical Centre+, Maastricht, The Netherlands

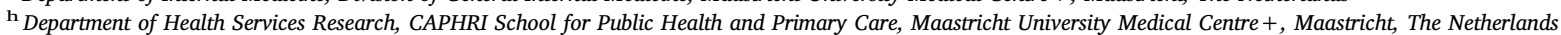 \\ ${ }^{\mathrm{i}}$ NUTRIM, School of Nutrition and Translational Research in Metabolism, Maastricht University Medical Centre+, Maastricht, The Netherlands \\ ${ }^{\mathbf{j}}$ MRC Life-course Epidemiology Unit, University of Southampton, Southampton, United Kingdom \\ ${ }^{\mathrm{k}}$ Department of Clinical Epidemiology, VieCuri Medical Centre, Venlo, The Netherlands
}

\section{A R T I C L E I N F O}

\section{Keywords:}

Incidence

Incidence rates

Gastrointestinal cancer

Type 2 diabetes mellitus

Epidemiology

\begin{abstract}
A B S T R A C T
Background: Patients with type 2 diabetes mellitus (T2DM) have been shown to have higher incidences of liver, pancreatic, and colorectal cancer compared to non-diabetic individuals. Current evidence is conflicting for other gastrointestinal (GI) cancers. Therefore, we aimed to determine incidence rates (IRs) of all GI cancers in patients with and without T2DM.

Methods: A cohort study was performed using the UK Clinical Practice Research Datalink (1988-2012). A cohort of antidiabetic drug users was matched at baseline to a non-diabetic cohort, by age, sex, and practice. Crude IRs and $95 \%$ confidence intervals (95\% CI) of GI cancers per 100,000 person-years were calculated stratified by age, sex, and calendar year.

Results: 333,438 T2DM and 333,438 non-diabetic individuals were analyzed. IRs of liver (IR 26, 95\% CI 24-28 vs. 8.9 , 95\% CI 7.7-10), pancreatic (IR 65, 95\% CI 62-69 vs. 31, 95\% CI 28-34), and colon cancer (IR 119, 95\% CI $114-124$ vs. 109, 95\% CI 104-114) were significantly higher in the diabetic compared to the non-diabetic cohort, whereas the IR of oesophageal cancer was significantly lower (IR 41, 95\% CI 39-44 vs. 47, 95\% CI 44-51). Sex-specific IRs of colon cancer remained significantly higher in men with T2DM, and IRs of esophageal cancer remained significantly lower in women with T2DM.

Conclusion: In this study, T2DM patients were shown to have higher crude IRs of liver, pancreatic and colon cancer, but not of gastric, biliary, and rectal cancer. Moreover, the lower observed IRs of oesophageal cancer in diabetic patients warrants further investigation.
\end{abstract}

\section{Introduction}

There is a growing body of evidence on an increased risk of cancer in type 2 diabetic patients, including gastrointestinal (GI) malignancies [1-7]. However, the data are conflicting for specific GI cancer sites, such as the upper gastrointestinal tract and biliary system. The strongest associations have been found for liver and pancreatic cancer, although ascertainment bias and reverse causality may have played an important role [8-10]. Furthermore, age-sex stratified analyses have not always been reported, despite the demonstration of age- and sexspecific differences in cancer risk, with GI cancer occurring more frequently at a higher age and more frequently in men [1].

Type 2 diabetic patients may have an increased risk of GI cancers through several common risk factors, such an older age, exposure to alcohol, smoking, a high caloric diet, lack of physical activity, and increased body mass index (BMI) [1]. In addition, site-specific risk factors that are more prevalent among diabetic patients may play an important role. These include gastro-oesophageal reflux disease in oesophageal

\footnotetext{
* Corresponding author at: Division of Pharmacoepidemiology and Clinical Pharmacology, Utrecht Institute for Pharmaceutical Sciences, Utrecht University, The Netherlands.

E-mail addresses: roy.dejong@maastrichtuniversity.nl (R.G.P.J. de Jong), f.devries@uu.nl (F. de Vries).
} 
cancer, Helicobacter pylori infections in gastric cancer, gallstone formation in biliary tract cancer, and non-alcoholic fatty liver disease or cirrhosis in hepatocellular carcinoma [11-14].

The underlying biological mechanisms that may explain the association between type 2 diabetes mellitus and cancer have yet to be further unraveled. In general, three pathophysiological mechanisms have been proposed which act through metabolic, hormonal and inflammatory pathways, namely: hyperglycaemia/hyperinsulinaemia, insulin/insulin-like growth factor (IGF) axis and chronic inflammation. Hyperinsulinaemia stimulates IGF-1 production, which may subsequently promote tumor growth by induction of cell proliferation and inhibition of apoptosis. Hyperinsulinaemia is also the hallmark of insulin resistance, which in turn stimulates the release of pro-inflammatory cytokines causing a pro-inflammatory state [1].

Most studies have reported relative measures of risk of cancer with diabetes, without a focus on the absolute numbers regarding the incidence of GI cancer in the diabetic population. To our knowledge population-based incidence rates of all subtypes of GI cancers in diabetic patients versus matched controls are unknown. Therefore, our aim was to determine incidence rates of GI malignancies for each site of the digestive tract in type 2 diabetic and non-diabetic individuals in the United Kingdom (UK).

\section{Materials and methods}

\subsection{Data source}

Data were obtained from the UK Clinical Practice Research Datalink (CPRD). The CPRD is an ongoing primary care database that comprises anonymized electronic medical records from British general practitioners since 1987, with coverage of over 11.3 million patients from 674 practices $[15,16]$. Currently, the population of active patients represents $6.9 \%$ of the total UK population. CPRD records include demographic information, medication prescription details, clinical events, preventive care provided, diagnostic tests, specialist referrals, hospital admissions, and major outcomes [16]. The accuracy and completeness of CPRD data have been well-validated [17,18]. The protocol of this study was approved by CPRD's Independent Scientific Advisory Committee (Protocol 15_143).

\subsection{Study population}

To examine GI cancer incidence rates (IRs) across anatomic subsite, age, sex, and calendar year among type 2 diabetic patients and nondiabetic individuals, we included a cohort of antidiabetic drug (ADD) users (diabetic cohort) and a (1:1) matched reference cohort using incidence sampling technique (Supplementary Fig. S1). The diabetic cohort consisted of all registered adult patients (aged $18+$ years) with at least one prescription for an ADD recorded in CPRD during valid data collection (January 1988-December 2012. The date of first ADD prescription defined start of follow-up (index date). Each diabetic patient was matched to a reference patient without any past recorded prescriptions for ADDs by sex, year of birth, and practice. Reference patients were assigned the same index date as their matched diabetic patient. Patients in the reference cohort could become diabetic patients if an ADD prescription was recorded. At the prescription date the patient was censored as a reference and matched, as a diabetic patient, to a new reference. Non-diabetic reference subjects could have suffered from any other disease than diabetes mellitus or those mentioned as exclusion criteria below.

Patients with a prescription for insulin at the index date, without a concomitant prescription for a non-insulin ADD, were excluded if (a) they had a recorded diagnosis for type 1 diabetes mellitus or (b) they were under 30 years of age at cohort entry. These patients were considered having type 1 diabetes mellitus. Secondly, all subjects with a history of the cancer of interest prior to cohort entry (i.e. all subjects with a history of gastric cancer when investigating gastric cancer) were excluded. Furthermore, all metformin only users who had a history of polycystic ovary syndrome (PCOS) prior to cohort entry were excluded, as they are more likely to receive metformin as a treatment for PCOS, instead of type 2 diabetes mellitus. In addition, we excluded diabetic patients without any subsequent prescriptions for an ADD (after the initial prescription recorded at baseline). All matched individuals of excluded subjects were excluded as well.

\subsection{Outcome}

All study participants were followed up from the index date to a diagnosis of a GI malignancy, the end of data collection, the date of transfer out of the practice area, or death, whichever came first. The first medical record for a GI cancer in CPRD after cohort entry was taken as the diagnosis date of a new case. Subsites of cancer were classified according to their anatomical location; i.e. cancer of the esophagus, stomach, liver, gallbladder and extrahepatic bile ducts (biliary), pancreas, small intestines, colon and rectum. A high level of validity for the recording of cancer in the CPRD has been previously reported [19].

\subsection{Statistical analyses}

To describe and compare both cohorts at baseline, we analyzed various lifestyle factors (smoking status, alcohol use, body mass index), a diagnosis of various comorbidities ever before (gallstone disease, gastro-esophageal reflux disease (GERD), Helicobacter pylori infection, hypertension, inflammatory bowel disease (IBD), chronic liver disease, and chronic pancreatitis), use of drugs during the past 6 months before start of follow-up (antihypertensives, aspirin, non-steroidal anti-inflammatory drugs (NSAIDs), proton-pump inhibitors, and statins), and if a subject had a colonoscopy for colorectal cancer screening purposes during the year before start of follow-up.

Overall, age-, sex-, and site-specific incidence rates (IR) per 100,000 person years (py) and incidence rate ratios (IRR) with $95 \%$ confidence intervals (CI) were calculated for GI cancers in the diabetic and reference cohort. IRRs were calculated by dividing the IR of the nondiabetic cohort by the IR of the type 2 diabetic cohort. Differences between IRs were tested for statistical significance using the normaltheory test $(\alpha<0.05)$ [20]. To assess secular trends, data were presented by age group and time period of cancer diagnosis. Age groups consisted of 5-year intervals, with the exception of those aged ' 18 through 29 years' (as cancer is rare these patients) and ending with ' $85+$ years'. Calendar time was broken down into six periods: 2001-2002, 2003-2004, 2005-2006, 2007-2008, 2009-2010, and 2011-2012. Time periods for 1988-2000 were not shown due to lower accuracy of CPRD database during that period. Due to a small number of small intestinal cancer cases, graphs for this cancer site are not shown as no reliable conclusions could be drawn. Furthermore, when the number of cases in a specific subgroup was less than six, data were not shown (suppressed) for reasons of patient privacy.

\subsection{Sensitivity analyses}

To prevent possible detection bias after the diagnosis of type 2 diabetes mellitus and account for possible reverse causality, a sensitivity analysis was performed by excluding the first year of follow-up after the index date from the analysis for all patients and subsequently calculating subsite- and sex-specific IRs during the remaining follow-up period. All data management and statistical analyses were conducted using SAS 9.2 (SAS Institute Inc., Cary, NC, USA).

\section{Results}

During more than 3.6 million person-years of follow-up, 10,977 GI 
Table 1

Baseline characteristics of the type 2 diabetic and non-diabetic cohorts.

\begin{tabular}{|c|c|c|c|}
\hline Characteristic & $\begin{array}{l}\text { Type } 2 \text { diabetic } \\
\text { cohort } \\
\left(\mathrm{n}=333,438^{\mathrm{a}}\right)\end{array}$ & $\begin{array}{l}\text { Non-diabetic cohort } \\
\left(\mathrm{n}=333,438^{\mathrm{a}}\right)\end{array}$ & $\mathrm{p}$-value \\
\hline $\begin{array}{l}\text { Median age at start } \\
\text { follow-up (years, } \\
\text { IQR) }\end{array}$ & $61.8(52-73)$ & $61.8(52-73)$ & \\
\hline Male (n, \%) & $183,297(55)$ & $183,297(55)$ & \\
\hline \multicolumn{4}{|l|}{$\begin{array}{l}\text { Type of antidiabetic } \\
\text { drug }^{\text {b }}(n, \%)\end{array}$} \\
\hline Metformin & $205,288(61.6)$ & & \\
\hline Sulfonylureas & $105,273(31.6)$ & & \\
\hline Thiazolidinediones & $7,632(2.3)$ & & \\
\hline Meglitinides & $1,017(0.3)$ & & \\
\hline DPP4-inhibitors & $1,584(0.5)$ & & \\
\hline GLP-1 analogues & $481(0.1)$ & & \\
\hline Insulin & $49,340(14.8)$ & & \\
\hline \multicolumn{4}{|l|}{$\begin{array}{l}\text { Body mass index (BMI) } \\
\text { category }(\mathrm{n}, \%)\end{array}$} \\
\hline$<20$ & $4,929(1.5)$ & $13,357(4.0)$ & \\
\hline $20-24$ & $45,379(13.6)$ & $87,337(26.2)$ & \\
\hline $25-29$ & $96,021(28.8)$ & $95,728(28.7)$ & \\
\hline $30-34$ & $73,749(22.1)$ & $36,223(10.9)$ & \\
\hline$\geq 35$ & $58,551(17.6)$ & $14,601(4.4)$ & \\
\hline Unknown & $54,809(16.4)$ & $86,192(25.8)$ & $<0.05$ \\
\hline \multicolumn{4}{|l|}{ Smoking status (n, \%) } \\
\hline Current & $69,225(20.8)$ & $70,518(21.1)$ & \\
\hline Former & $68,672(20.6)$ & $52,520(15.8)$ & \\
\hline Never & $147,391(44.2)$ & $150,281(45.1)$ & \\
\hline Unknown & $48,150(14.4)$ & $60,119(18.0)$ & $<0.05$ \\
\hline \multicolumn{4}{|l|}{ Alcohol use (n, \%) } \\
\hline Yes & $184,431(55.3)$ & $198,074(59.4)$ & \\
\hline No & $72,026(21.6)$ & $47,918(14.4)$ & \\
\hline Unknown & $76,981(23.1)$ & $87,446(26.2)$ & $<0.05$ \\
\hline \multicolumn{4}{|l|}{ Comorbidities (n, \%) } \\
\hline Gallstone disease & $9,173(2.8)$ & 5737 (1.7) & $<0.05$ \\
\hline $\begin{array}{l}\text { Gastro-esophageal reflux } \\
\text { disease }\end{array}$ & $29,463(8.8)$ & $26,638(8.0)$ & $<0.05$ \\
\hline $\begin{array}{l}\text { Helicobacter pylori } \\
\text { infection }\end{array}$ & $3,756(1.1)$ & $3543(1.1)$ & $<0.05$ \\
\hline Hypertension & $146,486(43.9)$ & $83,326(25.0)$ & $<0.05$ \\
\hline $\begin{array}{l}\text { Inflammatory bowel } \\
\text { disease }\end{array}$ & $3,090(0.9)$ & $2516(0.7)$ & $<0.05$ \\
\hline Chronic liver disease & $3,613(1.1)$ & $1190(0.4)$ & $<0.05$ \\
\hline Chronic pancreatitis & $1,419(0.4)$ & $270(0.1)$ & $<0.05$ \\
\hline \multicolumn{4}{|l|}{ Other drug-use $^{\mathrm{b}}(\mathrm{n}, \%)$} \\
\hline Antihypertensives & $192,086(57.6)$ & 102,911 (30.9) & $<0.05$ \\
\hline Aspirin & $92,558(27.8)$ & $41,511(12.4)$ & $<0.05$ \\
\hline NSAIDs $^{c}$ & $44,265(13.3)$ & $38,245(11.5)$ & $<0.05$ \\
\hline Proton-pump inhibitors & $53,164(15.9)$ & $35,558(10.7)$ & $<0.05$ \\
\hline Statins & $130,666(39.2)$ & $43,526(13.0)$ & $<0.05$ \\
\hline $\begin{array}{l}\text { Colorectal cancer } \\
\text { screening (n, \%) }\end{array}$ & $2903(0.9)$ & 3577 (1.1) & $<0.05$ \\
\hline
\end{tabular}

\footnotetext{
a Based on analysis of any gastrointestinal cancer.

b Multiple prescriptions on the index date occurred.

c Non-steroidal anti-inflammatory drugs (excluding apirin).
}

cancer cases were observed in 333,438 type 2 diabetic patients and 333,438 non-diabetic individuals. Baseline characteristics are presented in Table 1. Type 2 diabetic patients had on average a higher BMI, and a higher proportion was former smokers. Non-diabetic individuals were more often current smokers, and a higher proportion had used alcohol. In addition, statistical significant differences were seen between the type 2 diabetic and non-diabetic cohort in the histories of various comorbidities (e.g. gallstone disease, gastro-esophageal reflux disease, hypertension) at baseline, use of drugs (e.g. antihypertensives, aspirin, statins) during the 6 months before baseline, and colorectal cancer screening colonoscopy during the year before cohort entry.

\subsection{Cancer incidence by cancer site}

The IRs of any GI cancer (IR 330, 95\% CI 322-339 vs. 276, 95\% CI 268-284 per 100.000 py; IRR 1.20 , 95\% CI $1.15-1.24$ ), liver (IR 26 , 95\% CI $24-28$ vs. 8.9 , 95\% CI 7.7-10; IRR 2.87 , 95\% CI $2.40-3.44$ ), pancreatic (IR 65, 95\% CI 62-69 vs. 31, 95\% CI 28-34; IRR 2.12, 95\% CI 1.92-2.34), and colon cancer (IR 119, 95\% CI 114-124 vs. 109, 95\% CI 104-114; IRR 1.09, 95\% CI 1.03-1.16) were significantly higher ( $\mathrm{p}<0.05$ ) in the diabetic cohort compared to the reference cohort (Table 2). In contrast, the IR of esophageal cancer was significantly lower in the diabetic cohort compared to reference cohort (IR 41, 95\% CI $39-44$ vs. $47,95 \%$ CI $44-51$; IRR 0.87 , 95\% CI $0.79-0.96$, $\mathrm{p}<0.05$ ). Among the other subsites of GI cancer no significant differences in IRs between the diabetic and reference cohorts were seen. Similar results were found in a sensitivity analysis excluding 1 year of follow-up after the index date, except for pancreatic cancer in the diabetic cohort which declined to an IR of 48, 95\% CI 45-52 (data not shown). However, the difference in IRs for pancreatic cancer between the diabetic and reference cohort remained statistically significant.

\subsection{Cancer incidence by sex}

Men with type 2 diabetes mellitus had significantly higher IRs of any GI, liver, pancreatic and colon cancer compared to male reference patients (Table 2). In women with type 2 diabetes mellitus, significantly higher IRs were observed for any GI, liver, and pancreatic cancer compared to female reference patients. The lower IRs for esophageal cancer in the diabetic cohort only remained statistically significant in women, although in general, males had higher IRs of esophageal cancer than females. Among the other GI cancer sites no significant differences in IRs between the diabetic and reference cohorts were found after stratifying by sex.

\subsection{Cancer incidence by age}

Fig. 1 shows the site-specific IRs of GI cancers stratified by 5-year age groups for the diabetic and reference cohorts. Amongst all cancer sites, IRs increased with increasing age for both populations. Differences between the diabetic and reference cohort for IR at increasing age were most pronounced in liver, pancreatic and colon cancer. For other GI cancer sites, IRs by age overlapped between the two cohorts. Agespecific IRs of gastrointestinal cancers did not differ evidently when stratified by sex (data not shown).

\subsection{Cancer incidence over time}

IRs of any GI, liver, and pancreatic cancer in the diabetic cohort remained clearly elevated over time compared to the reference cohort (Fig. 2). Moreover, IRs of liver cancer more than doubled in time in the diabetic cohort, while remaining stable in the reference cohort. Also, trends of increasing IRs for colon cancer were observed in both the diabetic and reference cohort. In contrast, IRs of pancreatic cancer declined slightly over time in both cohorts, while IRs of any GI, esophageal, gastric, and biliary cancer remained more or less stable. In addition, IRs of esophageal cancer differed only in the time periods 2003-2004 and 2005-2006 between the two cohorts, being higher in the reference cohort. For other GI cancer subsites no noteworthy differences in IRs were seen between the diabetic and reference cohorts over time. 
Table 2

Overall, site- and sex-specific gastrointestinal cancer incidence rates in patients with and without type 2 diabetes mellitus.

\begin{tabular}{|c|c|c|c|c|c|c|c|c|c|c|}
\hline \multirow{2}{*}{$\begin{array}{l}\text { Overall } \\
\text { Cancer site }\end{array}$} & \multicolumn{4}{|c|}{ Type 2 diabetic cohort } & \multicolumn{4}{|c|}{ Non-diabetic cohort } & \multirow[b]{2}{*}{ IRR } & \multirow[b]{2}{*}{$95 \% \mathrm{CI}$} \\
\hline & Cases & PY & IR & $95 \% \mathrm{CI}$ & Cases & PY & IR & $95 \% \mathrm{CI}$ & & \\
\hline Any gastrointestinal $^{\mathrm{a}}$ & 6165 & $1,866,547$ & 330 & $322-339$ & 4812 & $1,744,473$ & 276 & $268-284$ & 1.20 & $1.15-1.24$ \\
\hline Esophagus $^{\mathrm{a}}$ & 785 & $1,900,616$ & 41 & $39-44$ & 842 & $1,776,232$ & 47 & $44-51$ & 0.87 & $0.79-0.96$ \\
\hline Stomach & 520 & $1,900,968$ & 27 & $25-30$ & 497 & $1,776,437$ & 28 & $26-31$ & 0.98 & $0.86-1.11$ \\
\hline Small intestines & 36 & $1,902,494$ & 1.9 & $1.4-2.6$ & 33 & $1,777,819$ & 1.9 & $1.3-2.6$ & 1.02 & $0.64-1.63$ \\
\hline Liver $^{\mathrm{a}}$ & 489 & $1,902,065$ & 26 & $24-28$ & 159 & $1,777,586$ & 8.9 & $7.7-10$ & 2.87 & $2.40-3.44$ \\
\hline Biliary & 232 & $1,902,096$ & 12 & $11-14$ & 202 & $1,777,298$ & 11 & $9.9-13$ & 1.07 & $0.89-1.30$ \\
\hline Pancreas $^{\mathrm{a}}$ & 1243 & $1,900,866$ & 65 & $62-69$ & 548 & $1,775,796$ & 31 & $28-34$ & 2.12 & $1.92-2.34$ \\
\hline Colon $^{\mathrm{a}}$ & 2243 & $1,882,327$ & 119 & $114-124$ & 1920 & $1,759,228$ & 109 & $104-114$ & 1.09 & $1.03-1.16$ \\
\hline Rectum & 1007 & $1,892,627$ & 53 & $50-57$ & 911 & $1,768,695$ & 52 & $48-55$ & 1.03 & $0.94-1.13$ \\
\hline Men & \multicolumn{4}{|c|}{ Type 2 diabetic cohort } & \multicolumn{4}{|c|}{ Non-diabetic cohort } & & \\
\hline Cancer site & Cases & PY & IR & $95 \%$ CI & Cases & PY & IR & $95 \% \mathrm{CI}$ & IRR & $95 \% \mathrm{CI}$ \\
\hline Any gastrointestinal $^{\mathrm{a}}$ & 3959 & $1,024,487$ & 386 & 375-399 & 3005 & 932,751 & 322 & $311-334$ & 1.20 & $1.14-1.26$ \\
\hline Esophagus & 593 & $1,044,940$ & 57 & $52-62$ & 600 & 951,374 & 63 & $58-68$ & 0.90 & $0.80-1.01$ \\
\hline Stomach & 362 & $1,045,280$ & 35 & $31-38$ & 347 & 951,552 & 36 & $33-41$ & 0.95 & $0.82-1.10$ \\
\hline Small intestines & 26 & $1,046,340$ & 2.5 & $1.7-3.6$ & 17 & 952,565 & 1.8 & $1.1-2.9$ & 1.39 & $0.76-2.57$ \\
\hline Liver $^{\mathrm{a}}$ & 386 & $1,045,964$ & 37 & $33-41$ & 106 & 952,328 & 11 & $9.2-13$ & 3.32 & $2.67-4.11$ \\
\hline Biliary & 120 & $1,046,173$ & 11 & $9.6-14$ & 104 & 952,338 & 11 & $9.0-13$ & 1.05 & $0.81-1.37$ \\
\hline Pancreas $^{\mathrm{a}}$ & 666 & $1,045,411$ & 64 & $59-69$ & 296 & 951,393 & 31 & 28-35 & 2.05 & $1.79-2.35$ \\
\hline Colon $^{\mathrm{a}}$ & 1408 & $1,034,745$ & 136 & $129-143$ & 1109 & 942,327 & 118 & $111-125$ & 1.16 & $1.07-1.25$ \\
\hline Rectum & 676 & $1,039,851$ & 65 & $60-70$ & 632 & 946,575 & 67 & $62-72$ & 0.97 & 0.87-1.09 \\
\hline Women & \multicolumn{4}{|c|}{ Type 2 diabetic cohort } & \multicolumn{4}{|c|}{ Non-diabetic cohort } & & \\
\hline Cancer site & Cases & PY & IR & $95 \% \mathrm{CI}$ & Cases & PY & IR & $95 \% \mathrm{CI}$ & IRR & $95 \% \mathrm{CI}$ \\
\hline Any gastrointestinal $^{\mathrm{a}}$ & 2206 & 842,060 & 262 & $251-273$ & 1807 & 811,721 & 223 & $213-233$ & 1.18 & $1.11-1.25$ \\
\hline Esophagus $^{\mathrm{a}}$ & 192 & 855,676 & 22 & $19-26$ & 242 & 824,858 & 29 & $26-33$ & 0.76 & 0.63-0.92 \\
\hline Stomach & 158 & 855,688 & 18 & $16-22$ & 150 & 824,885 & 18 & $15-21$ & 1.02 & $0.81-1.27$ \\
\hline Small intestines & 10 & 856,154 & 1.2 & $0.6-2.2$ & 16 & 825,254 & 1.9 & $1.2-3.2$ & 0.60 & $0.27-1.33$ \\
\hline Liver $^{\mathrm{a}}$ & 103 & 856,101 & 12 & $9.9-15$ & 53 & 825,258 & 6.4 & $4.9-8.4$ & 1.87 & $1.35-2.61$ \\
\hline Biliary & 112 & 855,923 & 13 & $11-16$ & 98 & 824,959 & 12 & $9.7-14$ & 1.10 & $0.84-1.44$ \\
\hline Pancreas $^{\mathrm{a}}$ & 577 & 855,455 & 67 & $62-73$ & 252 & 824,403 & 31 & $27-35$ & 2.21 & $1.90-2.56$ \\
\hline Colon & 835 & 847,581 & 99 & $92-105$ & 811 & 816,901 & 99 & $93-106$ & 0.99 & $0.90-1.09$ \\
\hline Rectum & 331 & 852,776 & 39 & $35-43$ & 279 & 822,119 & 34 & $30-38$ & 1.14 & $0.98-1.34$ \\
\hline
\end{tabular}

Abbreviations: PY (person-years), IR (incidence rate per 100,000 person-years), CI (confidence interval), IRR (incidence rate ratio).

a Statistically significant, $\mathrm{p}<0.05$.

\section{Discussion}

This study provides a comprehensive overview of IRs of GI cancers in people with and without diabetes mellitus using the CPRD database. Yearly, approximately one in every 300 type 2 diabetic patients in the UK developed a GI cancer. In general, IRs of any GI, liver, pancreatic, and colon cancer were higher in diabetic patients compared to nondiabetic individuals, with an IR of 26 per 100,000 person-years for liver cancer, an IR of 65 per 100,000 person-years for pancreatic cancer, and an IR of 119 for colon cancer in the diabetic population. In contrast, patients with type 2 diabetes mellitus had lower IRs of esophageal cancer compared to individuals without diabetes, however this difference was small, namely 6 esophageal cancers per 100,000 person-years. In the diabetic cohort, IRs for any GI, liver, pancreatic, and colon cancer were clearly elevated in almost all age groups and time periods compared to the non-diabetic cohort. In addition, an increasing time trend was observed for liver cancer in the diabetic cohort, for colon cancer in both cohorts, whereas for pancreatic cancer a decreasing trend was observed in both cohorts.

A substantial number of studies have reported increased risks of liver, pancreatic, and colon cancer in patients with type 2 diabetes mellitus independent of other risk factors [21-29]. As a result, type 2 diabetes mellitus is considered as a risk factor for these cancer types [1]. Our results support this claim, especially for liver and pancreatic cancer where the differences in IRs were most pronounced. Furthermore, these differences became more apparent when stratified by age and time period. However, more recent studies have shown that part of the association might be affected by detection bias or reverse causation $[8,30]$. To minimize these biases, a sensitivity analysis was performed, excluding the first year of follow-up after the index date, which did not change the results, except for a substantial, but non-significant decrease in the IR of pancreatic cancer in the diabetic cohort. This might suggest that reverse causality plays a role in pancreatic cancer.

Insulin is thought to be one of the major hormonal contributors to the diabetes-cancer link [1]. On the one hand, both the liver and the pancreas are exposed to higher levels of endogenous insulin compared to other organs via the portal venous system, possibly leading to an increased risk of cancer [1]. On the other hand, both liver and pancreatic cancers are known to impair glucose regulation and induce diabetes as well $[8,31]$. Therefore, the association between type 2 diabetes mellitus and these cancers may very well be bidirectional.

As for colorectal cancer (CRC), a recent umbrella review of metaanalyses showed that meta-analyses reporting an increased risk of CRC in diabetics are robust, showing an absolute risk increase of around 30 percent [32]. More importantly, because of the sheer number of incident CRC cases worldwide, the growing number of type 2 diabetics, and the increasing time trend observed in this study, this might have an enormous impact on the world population and global health care systems. Furthermore, since CRC screening programs have been implemented or are at present being implemented in an increasing number of countries, more targeted and tailored screening of diabetics should be considered in the near future. 

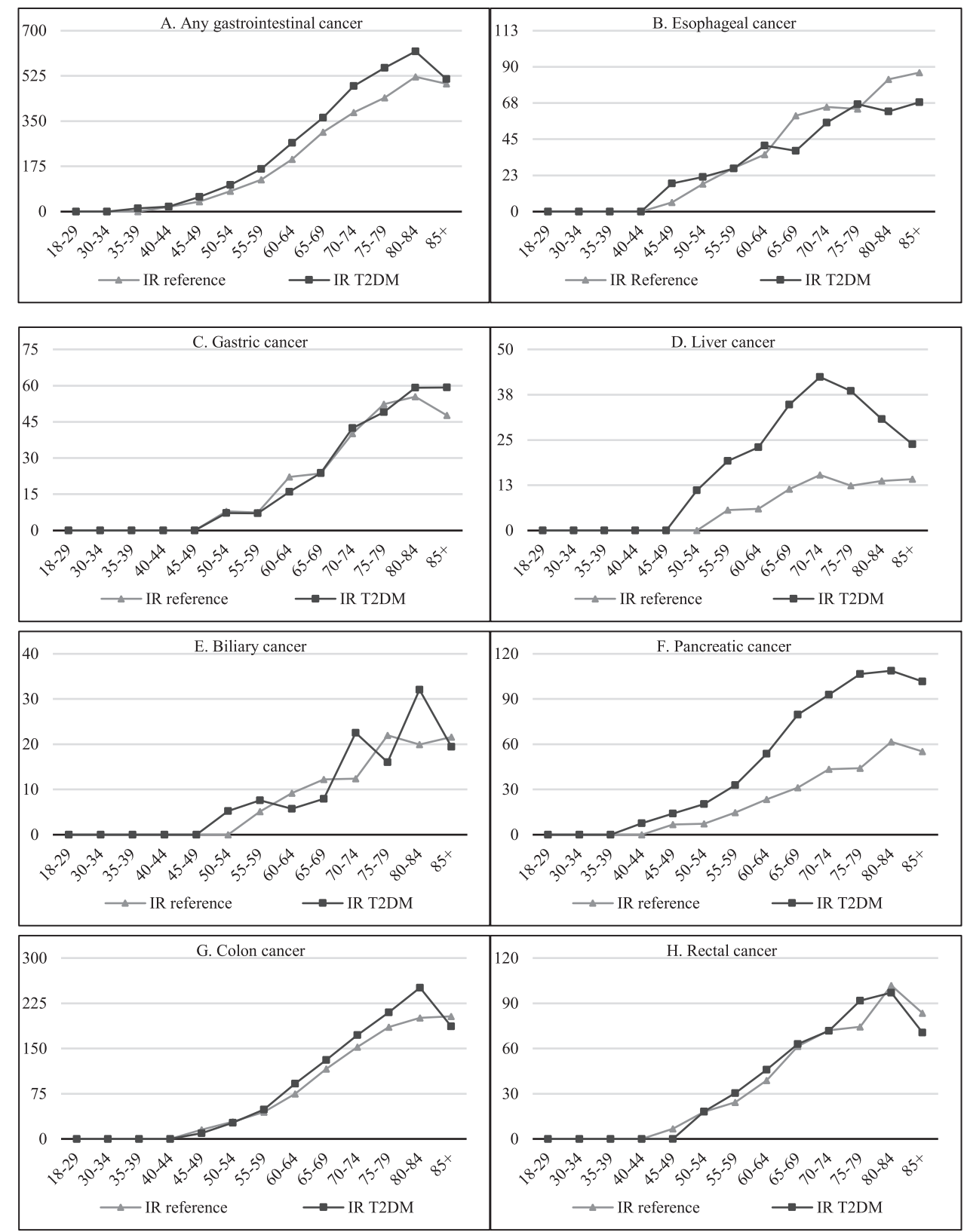

Fig. 1. Overall and site-specific GI cancer incidence rates stratified by 5 -year age categories (x-axis). The yaxis indicates the incidence rate in number of events per 100,000 person-years. GI: gastrointestinal, T2DM:Type 2 diabetes mellitus, IR: incidence rate. Black line: type 2 diabetic cohort, Grey line: reference cohort.

In contrast to the other gastrointestinal cancer sites, we observed a significantly lower IR of esophageal cancer in patients with type 2 diabetes mellitus compared to non-diabetic individuals, although the observed difference was small (IR 41 vs. 47 per 100,000 py) and did not differ much after stratification by sex. Lifestyle factors such as smoking and alcohol use are important risk factors for esophageal cancer, especially for squamous cell carcinoma [33]. At baseline these factors differed significantly between the diabetic and reference cohorts, the latter being more often current smokers and users of alcohol, which could explain the observed difference in IRs. On the other hand, type 2 diabetic patients had a higher BMI compared to non-diabetic individuals, predisposing them to a higher risk of gastro-esophageal reflux disease, reflux esophagitis, and subsequently Barrett's esophagus and adenocarcinoma of the esophagus [34-36]. Unfortunately, histologic subtypes of esophageal cancer could not be analyzed in this study. Indeed, it is known that the two main histologic subtypes of esophageal cancer (squamous cell carcinoma and adenocarcinoma) show marked epidemiological, pathogenic, and biological differences [34]. For instance, the incidence of esophageal adenocarcinoma has increased in recent years, whereas the incidence of esophageal squamous cell carcinoma has markedly decreased [37]. In general, a modestly increased risk of esophageal cancer in type 2 diabetic patients (summary relative risk 1.30, 95\% CI: 1.12-1.50) compared to non-diabetic individuals has been observed, although not remaining significant after stratification for sex [34].

The major strength of this study is the use of the CPRD, one of the world's largest population-based databases. The CPRD contains approximately $7 \%$ of the UK population, and is representative of the UK general population in terms of age, sex, and ethnicity [15,16]. In addition, a high level of validity for the recording of cancer in the CPRD has been previously reported, with cancer diagnosis being valid and accurate more than $90 \%$ of the time [19]. However, potential ascertainment or misclassification bias could not be ruled out. Furthermore, we reported the absolute number of cases and IRs of GI cancers instead 

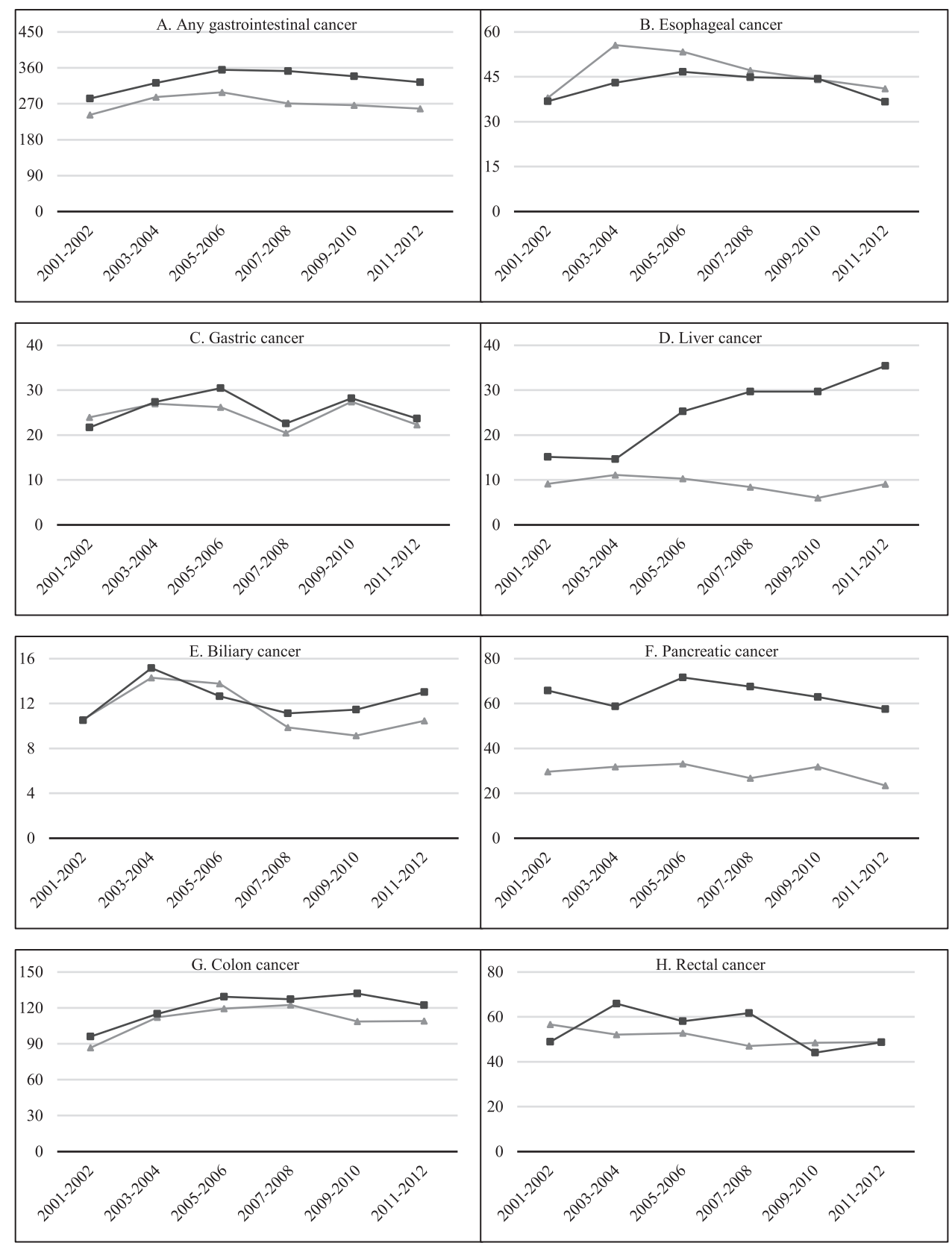

Fig. 2. Time trends in any and site-specific IRs of GI cancer in the diabetic and non-diabetic cohort, by calendar period (2001-2012; x-axis). The y-axis indicates the IR in number of events per 100,000 personyears.GI: gastrointestinal, IR: incidence rate. Black line: type 2 diabetic cohort, Grey line: reference cohort.

of relative risks, to adequately show the difference in IRs between both populations.

The main limitation of this study is that causal interpretation of the findings is restricted. Secondly, diabetic status was defined by the recorded prescription of ADDs. Therefore, misclassification of exposure, and thereby diabetic status, might have occurred since the derived prescription from the GP system may not have been dispensed by the pharmacy, or actually used by the subject. However, most diabetic patients require chronic medication for adequate glycaemic control, making misclassification less likely for those being prescribed drugs on a regular basis. Also, it is possible that type 2 diabetic patients not treated with ADDs or undetected diabetes mellitus were included in the reference population. This could have biased the results by diminishing the difference in IRs between cohorts. Additionally, controls could have suffered from any other disease than diabetes mellitus or those mentioned as exclusion criteria. This could have impacted their survival and therewith their chance of developing cancer. This might explain the somewhat lower total person-years of follow-up in controls. Furthermore, it is possible that the results are confounded, as we could not take into account any risk factors (e.g. smoking, consumption of alcohol, obesity, drug use, and comorbidities) that might contribute to a higher cancer rate in diabetic patients. Also, type 2 diabetic patients and controls were matched on general practice, but residual confounding by socio-economic status could still be present. In addition, the observed IRs in the reference cohort were generally higher compared to age-standardized incidence rates (ASRs) of GI cancers in the general population of the UK [38]. We calculated ASRs using the direct method according to the Segi-Doll world standard population to verify whether IRs were comparable to previously reported ASRs in the UK $[39,40]$. After age-standardization, ASRs of the reference cohort were in line with ASRs in the UK as reported in the tenth volume of the Cancer Incidence in Five Continents series, published by the International 
Agency for Research on Cancer and the International Association of Cancer Registries (data not shown) [38].

This large retrospective population-based cohort study shows that patients with type 2 diabetes mellitus have higher incidence rates for liver, pancreatic, and colon cancer compared to non-diabetic individuals. In general, one in every 300 type 2 diabetic patients developed a GI cancer every year. Furthermore, we found no differences in IRs between type 2 diabetic and non-diabetic individuals for gastric, biliary, and rectal cancer. Conversely, slightly lower IRs were observed in type 2 diabetic patients for esophageal cancer. The results of this study underline the importance of clinical awareness for liver, pancreatic, and colon cancer in the type 2 diabetic population. In addition, the lower observed IRs of esophageal cancer in diabetic patients warrants further investigation.

\section{Author contributions}

[RJ] and [PP] contributed to the formulation of the study design, data analysis, interpretation of the results, and writing of the manuscript. [AB, AM, FV, and $\mathrm{MJ}$ ] contributed to the formulation of the study design, interpretation of the results, and critical revision of the manuscript. [MB and $\mathrm{HH}]$ contributed to the interpretation of the results and critical revision of the manuscript.

\section{Funding}

Data were obtained from CARING (Cancer Risk and Insulin analoGues) project, which received funding from the European Community's Seventh Framework Programme (FP-7) under grant agreement number 282526. The funding source had no role in study design, data collection, data analysis, data interpretation or writing of the report.

\section{Conflict of interest}

Paul J.H.L. Peeters' employment at Utrecht University was funded by the CARING project. Marie L. De Bruin is a senior researcher at Utrecht University and conducts research in collaboration with the WHO Collaborating Centre for pharmaceutical policy and regulation. This Centre receives no direct funding or donations from private parties, including pharma industry. Research funding from public-private partnerships, e.g. IMI, TI Pharma (www.tipharma.nl) is accepted under the condition that no company-specific product or company related study is conducted. The Centre has received unrestricted research funding from public sources, e.g. Netherlands Organization for Health Research and Development (ZonMW), the Dutch Health Care Insurance Board (CVZ), EU 7th Framework Program (FP7), Dutch Medicines Evaluation Board (MEB), and Dutch Ministry of Health.

None of the above mentioned funding sources had a role in the design, conduct, analysis, or reporting of this study. All other authors have no relevant conflict of interest to disclose.

\section{Appendix A. Supplementary data}

Supplementary material related to this article can be found, in the online version, at doi: https://doi.org/10.1016/j.canep.2018.04.008.

\section{References}

[1] E. Giovannucci, D.M. Harlan, M.C. Archer, R.M. Bergenstal, S.M. Gapstur, L.A. Habel, et al., Diabetes and cancer: a consensus report, CA. Cancer J. Clin. 60 (2010) 207-221.

[2] S.L. Habib, M. Rojna, Diabetes and risk of cancer, ISRN Oncol. 2013 (2013) 583786.

[3] M.M. Jamal, E.J. Yoon, K.J. Vega, M. Hashemzadeh, K.J. Chang, Diabetes mellitus as a risk factor for gastrointestinal cancer among American veterans, World J. Gastroenterol. : WJG 15 (2009) 5274-5278.

[4] C.C. Chiu, C.C. Huang, Y.C. Chen, T.J. Chen, Y. Liang, S.J. Lin, et al., Increased risk of gastrointestinal malignancy in patients with diabetes mellitus and correlations with anti-diabetes drugs: a nationwide population-based study in Taiwan, Intern. Med. 52 (2013) 939-946.

[5] P.J. Peeters, M.T. Bazelier, H.G. Leufkens, F. de Vries, M.L. De Bruin, The risk of colorectal cancer in patients with type 2 diabetes: associations with treatment stage and obesity, Diabetes Care 38 (2015) 495-502.

[6] L.M. Knapen, J. van Dalem, Y.C. Keulemans, N.P. van Erp, M.T. Bazelier, M.L. De Bruin, et al., Use of incretin agents and risk of pancreatic cancer: a population-based cohort study, Diabetes Obes. Metab. 18 (3) (2015) 258-265.

[7] J. Starup-Linde, O. Karlstad, S.A. Eriksen, P. Vestergaard, H.K. Bronsveld, F. de Vries, et al., CARING (CAncer Risk and INsulin analoGues): the association of diabetes mellitus and cancer risk with focus on possible determinants - a systematic review and a meta-analysis, Curr. Drug Saf. 8 (2013) 296-332.

[8] J.A. Johnson, S.L. Bowker, K. Richardson, C.A. Marra, Time-varying incidence of cancer after the onset of type 2 diabetes: evidence of potential detection bias, Diabetologia 54 (2011) 2263-2271.

[9] A. Nicolucci, Epidemiological aspects of neoplasms in diabetes, Acta Diabetol. 47 (2010) 87-95.

[10] P. Vigneri, F. Frasca, L. Sciacca, G. Pandini, R. Vigneri, Diabetes and cancer, Endocr. Relat. Cancer 16 (2009) 1103-1123.

[11] J. Lagergren, R. Bergstrom, A. Lindgren, O. Nyren, Symptomatic gastroesophageal reflux as a risk factor for esophageal adenocarcinoma, N. Engl. J. Med. 340 (1999) 825-831.

[12] C. Bosetti, V. Rosato, J. Polesel, F. Levi, R. Talamini, M. Montella, et al., Diabetes mellitus and cancer risk in a network of case-control studies, Nutr. Cancer 64 (2012) 643-651.

[13] S.W. Lin, N.D. Freedman, A.R. Hollenbeck, A. Schatzkin, C.C. Abnet, Prospective study of self-reported diabetes and risk of upper gastrointestinal cancers, Cancer Epidemiol. Biomark. Prev. 20 (2011) 954-961.

[14] K. Hemminki, X. Li, J. Sundquist, K. Sundquist, Risk of cancer following hospitalization for type 2 diabetes, Oncol. 15 (2010) 548-555.

[15] J. Parkinson, S. Davis, T.P. van Staa, The general practice research (GPRD) database: now and the future [online text], in: R.D. Mann, E.B. Andrews (Eds.), Pharmacovigilance, 2nd ed., John Wiley \& Sons, Hoboken, 2007, pp. 341-348.

[16] E. Herrett, A.M. Gallagher, K. Bhaskaran, H. Forbes, R. Mathur, T. van Staa, et al., Data Resource profile: Clinical Practice Research Datalink (CPRD), Int. J. Epidemiol. 44 (3) (2015) 827-836.

[17] N.F. Khan, S.E. Harrison, P.W. Rose, Validity of diagnostic coding within the general practice research database: a systematic review, Br. J. Gen. Pract. J. R. Coll. Gen. Practition. 60 (2010) e128-e136.

[18] E. Herrett, S.L. Thomas, W.M. Schoonen, L. Smeeth, A.J. Hall, Validation and validity of diagnoses in the General practice research database: a systematic review, Br. J. Clin. Pharmacol. 69 (2010) 4-14.

[19] A. Dregan, H. Moller, T. Murray-Thomas, M.C. Gulliford, Validity of cancer diagnosis in a primary care database compared with linked cancer registrations in England. Population-based cohort study, Cancer Epidemiol. 36 (2012) 425-429.

[20] B. Rosner, Fundamentals of Biostatisticsm, sixth edition, Duxbury Press, 2006, pp. 751-752.

[21] J. Luo, R. Chlebowski, S. Liu, K.A. McGlynn, N. Parekh, D.L. White, et al., Diabetes mellitus as a risk factor for gastrointestinal cancers among postmenopausal women, Cancer Causes Control CCC 24 (2013) 577-585.

[22] A.A. Ogunleye, S.A. Ogston, A.D. Morris, J.M. Evans, A cohort study of the risk of cancer associated with type 2 diabetes, Br. J. Cancer 101 (2009) 1199-1201.

[23] S.C. Larsson, N. Orsini, A. Wolk, Diabetes mellitus and risk of colorectal cancer: a meta-analysis, J. Natl. Cancer Inst. 97 (2005) 1679-1687.

[24] E.A. Atchison, G. Gridley, J.D. Carreon, M.F. Leitzmann, K.A. McGlynn, Risk of cancer in a large cohort of U.S. veterans with diabetes, Int. J. Cancer J. Int. Du Cancer. 128 (2011) 635-643.

[25] L. Deng, Z. Gui, L. Zhao, J. Wang, L. Shen, Diabetes mellitus and the incidence of colorectal cancer: an updated systematic review and meta-analysis, Digest. Dis. Sci. 57 (2012) 1576-1585.

[26] J.W. Elena, E. Steplowski, K. Yu, P. Hartge, G.S. Tobias, M.J. Brotzman, et al, Diabetes and risk of pancreatic cancer: a pooled analysis from the pancreatic cancer cohort consortium, Cancer Causes Control CCC 24 (2013) 13-25.

[27] D. Li, H. Tang, M.M. Hassan, E.A. Holly, P.M. Bracci, D.T. Silverman, Diabetes and risk of pancreatic cancer: a pooled analysis of three large case-control studies, Cancer Causes Control CCC 22 (2011) 189-197.

[28] J. Chen, Y. Han, C. Xu, T. Xiao, B. Wang, Effect of type 2 diabetes mellitus on the risk for hepatocellular carcinoma in chronic liver diseases: a meta-analysis of cohort studies, Eur. J. Cancer Prev. 24 (2015) 89-99.

[29] S. Schlesinger, K. Aleksandrova, T. Pischon, M. Jenab, V. Fedirko, E. Trepo, et al., Diabetes mellitus, insulin treatment, diabetes duration, and risk of biliary tract cancer and hepatocellular carcinoma in a European cohort, Ann. Oncol. 24 (2013) 2449-2455.

[30] K.M. De Bruijn, R. Ruiter, C.E. de Keyser, A. Hofman, B.H. Stricker, C.H. van Eijck, Detection bias may be the main cause of increased cancer incidence among diabetics: results from the Rotterdam study, Eur. J. Cancer 50 (2014) 2449-2455.

[31] D. Li, Diabetes and pancreatic cancer, Mol. Carcinog. 51 (2012) 64-74.

[32] K.K. Tsilidis, J.C. Kasimis, D.S. Lopez, E.E. Ntzani, J.P. Ioannidis, Type 2 diabetes and cancer: umbrella review of meta-analyses of observational studies, BMJ 350 (2015) g7607.

[33] J. Steevens, L.J. Schouten, R.A. Goldbohm, P.A. van den Brandt, Alcohol consumption, cigarette smoking and risk of subtypes of oesophageal and gastric cancer: a prospective cohort study, Gut 59 (2010) 39-48.

[34] W. Huang, H. Ren, Q. Ben, Q. Cai, W. Zhu, Z. Li, Risk of esophageal cancer in diabetes mellitus: a meta-analysis of observational studies, Cancer Causes Control 
CCC 23 (2012) 263-272

[35] F. Mearin, J.R. Malagelada, Gastroparesis and dyspepsia in patients with diabetes mellitus, Eur. J. Gastroenterol. Hepatol. 7 (1995) 717-723.

[36] T. Kamiya, H. Adachi, M. Hirako, M. Shikano, E. Matsuhisa, T. Wada, et al., Impaired gastric motility and its relationship to reflux symptoms in patients with nonerosive gastroesophageal reflux disease, J. Gastroenterol. 44 (2009) 183-189.

[37] A.A. Botterweck, L.J. Schouten, A. Volovics, E. Dorant, P.A. van Den Brandt, Trends in incidence of adenocarcinoma of the oesophagus and gastric cardia in ten European countries, Int. J. Epidemiol. 29 (2000) 645-654.
[38] D. Forman, F. Bray, D.H. Brewster, C. Gombe Mbalawa, B. Kohler, M. Piñeros, et al., Cancer Incidence in Five Continents, Vol. X. IARC Scientific Publication No 164, International Agency for Research on Cancer, Lyon, 2014.

[39] M. Segi, I. Fukushima, M. Kurihara, A proposal on a calculation method to be applied by geographical comparison of cancer mortality, Tohoku. J. Exp. Med. 60 (1954) 307-310.

[40] R. Doll, P. Payne, J. Waterhouse, Cancer Incidence in Five Continents: A Technical Report, Springer-Verlag (for UICC, Berlin, 1966. 